\title{
Cholera hotspots and surveillance constraints contributing to recurrent epidemics in Tanzania
}

\author{
Yaovi M. G. Hounmanou ${ }^{1 *}$ (D, Kåre Mølbak ${ }^{1,2}$, Jonas Kähler ${ }^{2}$, Robinson H. Mdegela ${ }^{3}$, John E. Olsen ${ }^{1}$ \\ and Anders Dalsgaard ${ }^{1,4}$
}

\begin{abstract}
Objective: We described the dynamics of cholera in Tanzania between 2007 and 2017 and assessed the weaknesses of the current surveillance system in providing necessary data in achieving the global roadmap to 2030 for cholera control.

Results: The Poisson-based spatial scan identified cholera hotspots in mainland Tanzania. A zero-inflated Poisson regression investigated the relationship between the incidence of cholera and available demographic, socio-economic and climatic exposure variables. Four cholera hotspots were detected covering 17 regions, home to 28 million people, including the central regions and those surrounding the Lakes Victoria, Tanganyika and Nyaza. The risk of experiencing cholera in these regions was up to 2.9 times higher than elsewhere in the country. Regression analyses revealed that every $100 \mathrm{~km}$ of water perimeter in a region increased the cholera incidence by $1.5 \%$. Due to the compilation of surveillance data at regional level rather than at district, we were unable to reliably identify any other significant risk factors and specific hotspots. Cholera high-risk populations in Tanzania include those living near lakes and central regions. Successful surveillance require disaggregated data available weekly and at district levels in order to serve as data for action to support the roadmap for cholera control.
\end{abstract}

Keywords: Cholera, Tanzania, Spatial-temporal analysis, Great Lakes, Cholera dynamics

\section{Introduction}

Half of all cholera reported cases from Africa between 1970 and 2011 were notified by seven countries, including Tanzania, which has remained one of the top cholera reporting countries until 2018 [1,2]. Since the seventh cholera pandemic reached the country in 1974, Tanzania reports outbreaks almost every year and has notified over 250,000 cases and 13,078 deaths by $2018[1,3]$.

In 2017, the global task force on cholera control established a roadmap to 2030 for elimination of cholera with Tanzania being one of the 48 targeted endemic countries [4]. The strategies recommended by the task force include

\footnotetext{
*Correspondence: gil@sund.ku.dk

${ }^{1}$ Department of Veterinary and Animal Sciences, Faculty of Health and Medical Sciences, University of Copenhagen, 1870 Frederiksberg C, Copenhagen, Denmark

Full list of author information is available at the end of the article
}

rigorous surveillance for early detection and response with emphasis on cholera high-risk populations at local levels for optimal interventions $[4,5]$. Therefore, prioritizing high-risk areas in endemic countries can increase the efficiency of cholera control programs because only detailed analysis of local data in each country can provide better understanding of local cholera dynamics for effective control [1]. Successful identification of high-risk areas, however depends on robust surveillance, which is difficult to achieve in many countries including Tanzania due to the stigma related to cholera reporting and associated economic losses in the tourism sector leading to inaccurate reporting in many countries [5]. Nevertheless, a number of spatio-temporal studies have been conducted with surveillance data in Uganda, in the Democratic Republic of Congo (DRC), in India and on Zanzibar islands to contribute with scientific knowledge

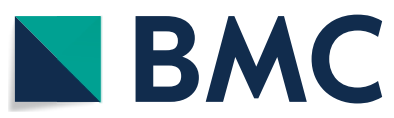

C The Author(s) 2019. This article is distributed under the terms of the Creative Commons Attribution 4.0 International License (http://creativecommons.org/licenses/by/4.0/), which permits unrestricted use, distribution, and reproduction in any medium, provided you give appropriate credit to the original author(s) and the source, provide a link to the Creative Commons license, and indicate if changes were made. The Creative Commons Public Domain Dedication waiver (http://creativecommons.org/ publicdomain/zero/1.0/) applies to the data made available in this article, unless otherwise stated. 
enabling these countries to get rid of epidemic cholera by 2030 [6-10].

In the present study, we analyzed 11 years of available cholera surveillance data between 2007 and 2017 from all regions of mainland Tanzania. Together with geographical, climatic and socio-demographic data, hotspots identification and risk factors analyses were performed to describe the epidemiology of cholera in Tanzania and address weaknesses in the current surveillance system in achieving the objectives of the global roadmap to 2030 for elimination of cholera in the country.

\section{Main text \\ Methods \\ Data collection}

Retrospective data of cholera cases and deaths compiled at regional levels from 2007 to 2017 were obtained from the Epidemiology and Disease Control Section of the Tanzanian Ministry of Health. Data included in this study are those reported based on the WHO standards for cholera case definition and are described as follows:

(i) Patient aged 5 years or more with severe dehydration and acute watery diarrhea or individual who died from the same symptoms in an area without a confirmed outbreak;

(ii) A patient aged 2 years or above having acute watery diarrhea, with or without vomiting in an area where there is an ongoing cholera epidemic;

(iii) Confirmation of Vibrio cholerae O1 isolated in the stool of suspected patients.

Population data for the country's 25 regions (Additional file 1) were extracted from the latest 2012 Population and Housing Census report from the National Bureau of Statistics [11]. Using the inter-censual growth rate of each region, annual population in each region was calculated to estimate the population at risk per year in each region. Proportion of households with access to improved drinking water and households with access to improved toilets were retrieved and included in the analysis. For indicators of socioeconomic status, proportion of households possessing mobile phone and television during the census was used (Additional file 1).

Rainfall data were obtained from the Tanzanian Meteorological Agency, where annual rainfall data in millimeter was obtained per region for each of the 11 years.

Country shape files were obtained from the National Bureau of Statistics [11]. GIS data of the water areas were obtained online from diva-GIS website [12]. All shape files were analyzed in quantum GIS version 2.18, Las Palmaras (https://qgis.org/en/site/) for validity. In QGIS, regional and waterbodies polygons were joined using the Union vector to determine two new variables: total water area and water perimeter found in each region and included in the analysis (Additional file 1).

\section{Data analyses}

Identification of high risk clusters (hotspots) were performed using SaTScan v 9.6 (https://www.satscan.org/) with the Poisson-based spatial scan. The centroid coordinates of each region was detected from the regional shape-file using QGIS 2.18. These coordinates were used as the geographic references of the regions. In the Poisson model, the expected cholera cases in each part of the regions are assumed proportional to the population size of the region. The model detected clusters in a multidimensional point process and allowed variable window sizes to scan for cholera cases within the region. Variable window size was used, because a prior estimation of the size of the area covered by a cluster was not known. A circular scan window was selected, which moved over the entire region with a radius that varied from zero to $25 \%$ of the population at risk. The clusters covered areas with lower rates outside a circular scan window compared with higher rates inside the circle. The likelihood ratio for a specific window was determined as previously described $[6,8]$. The output files were displayed in Google Map.

Poisson regression was used for the analyses of potential risk factors for cholera. In this model, the total number of cases (2007 to 2017) reported at the regional level was the dependent variable, exposure variables were obtained from the 2012 census as well as parameters from the geographical analysis (Fig. 1a). The logarithm to the population was included as an offset variable and thereby the analysis represents a log-linear model of the incidence. We used a zero-inflated Poisson regression for the analysis of the relation between rainfall in the year before reporting and the number of reported cases. In both models, we applied robust standard errors. In the analysis of the relation between rainfall and number of reported cases, we adjusted the standard error for the 25 regions because it was assumed that there is less variance within a region than between regions. The log to the estimated yearly population was included as offset variable. Stata version 14 was used for the regression models.

\section{Results and discussion}

From 2007 to 2017, mainland Tanzania reported 39,444 cholera cases with 600 deaths, giving a case fatality rate of $1.5 \%$ and an average annual incidence rate of 8.39 per 100,000 people. A similar analysis of 10 years data from the DRC revealed a higher number of cases and case fatality rates of $1.9 \%$ [9]. DRC is the country reporting the most cholera cases in Africa and for many years have been a devastated country because of wars and 


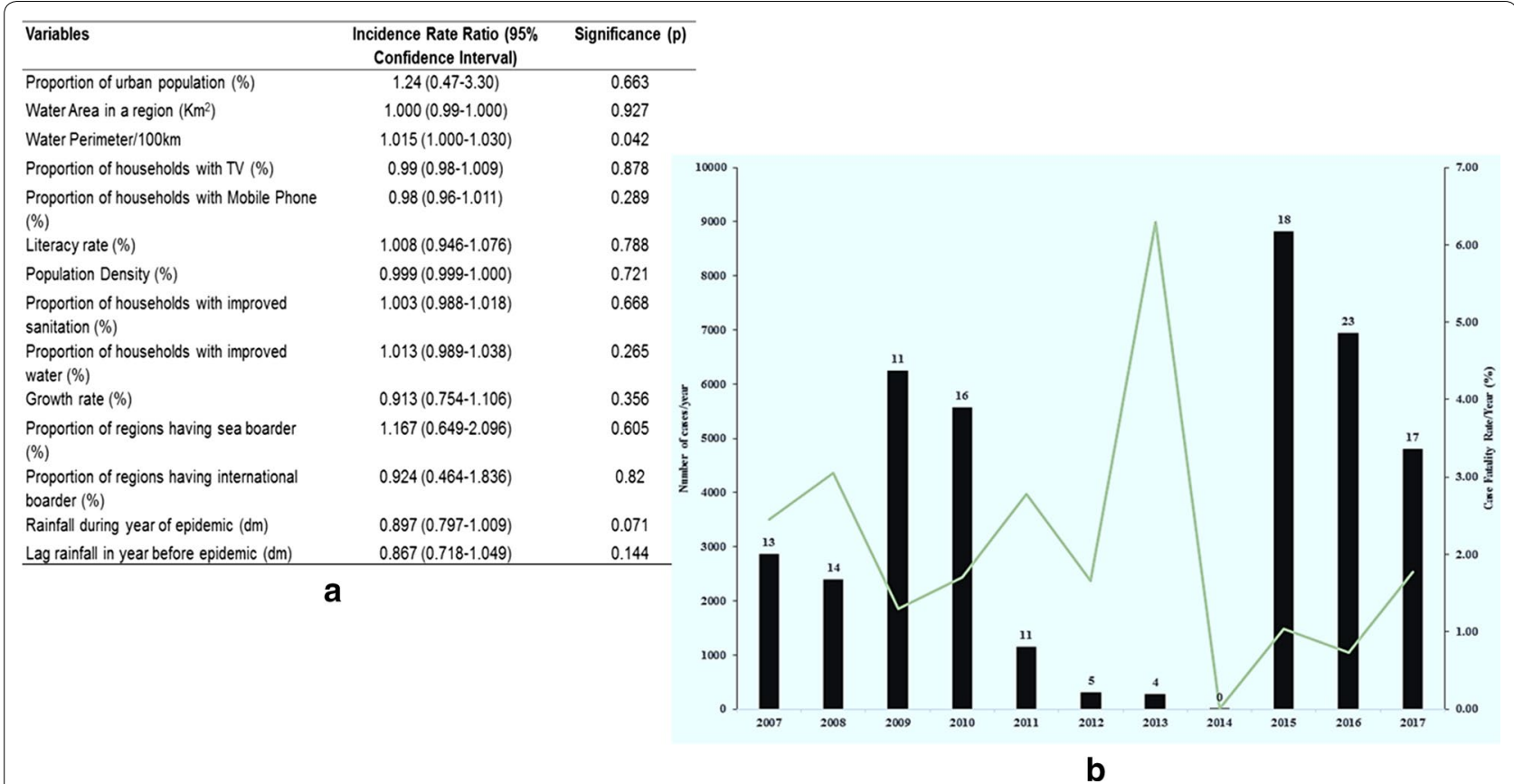

Fig. 1 a Poisson regression of determinants for cholera reporting in Tanzania based on regional data. b Number of cholera cases (bars) and case fatality rates (line) per year in mainland Tanzania. Numbers of affected regions are shown on top of each bar

population displacement associated with higher risks for cholera [9]. However, the relatively lower incidence in Tanzania could be attributed to the fact that reporting cholera has negative impacts on tourism and exports of affected countries, leading to underreporting [5]. In 2016, 23 of the 25 regions in Tanzania reported cholera but most cases (8821) were reported in 2015 (Fig. 1b). The highest case fatality rate was recorded in $2013(6.3 \%)$ when only 270 cases were reported countrywide. It is likely that initial cases in an outbreak experience elevated case-fatality, whereas the official recognition of an outbreak leads to improved management and increased case-finding thereby identifying milder cases as well. At regional level, Shinyanga had the highest case fatality rate in the study period (7\%) while Dodoma reported the highest number of cases (5988), although $94.1 \%$ of these cases were recorded exclusively between 2015 and 2017 where the countrywide incidence reached 14.2 per 100,000 people (Fig. 1b). Every region except Kagera, reported cholera at least once during the 11 years. Fifteen regions reported cholera in at least six of the 11 years and can be considered cholera endemic regions $[6,8]$.

Spatial analyses revealed four high-risk areas of different sizes (Fig. 2a). Seventeen regions had their centroids within the identified hotspots. The risk of having cholera in these regions was up to 2.89 times higher compared to elsewhere in the country $(\mathrm{p}<0.0001$, Fig. $2 \mathrm{~b})$. The hotspot with highest risk of cholera was Dodoma region, including its neighboring regions where high magnitude outbreaks were recorded after 2015. This corroborates the role of urbanization and population displacements in cholera dynamics [13-15]. The increasing number of outbreaks in 2015-2017 in Dodoma coincides with the time where the Tanzanian government moved offices to Dodoma as the capital city of the country. This was associated with significant movement of government employees and affiliated business from Dar es Salaam, but also a number of people working with the construction of new government office buildings [16].

Approximately 28 million people live in the regions found in the hotspots based on the 2012 census. Three of the four hotspots were around major lakes in the country mainly Lake Victoria, Tanganyika and Nyasa. Living near a lake was also reported in Uganda, the DRC and elsewhere as a factor associated with increased cholera incidence $[8,17,18]$.

According to existing literature, Dar es Salaam is one of the endemic cities experiencing cholera outbreaks in Tanzania [19]. This city was however not identified in our analysis as part of the hotspot areas. Such a discrepancy reveal one of the limitations of the data and weaknesses of the existing surveillance system in which cholera reports were aggregated at regional level rather than at district level. The observed clusters should therefore be treated with caution. Reliable disease hotspot identification cannot be effective when surveillance and risk factor 


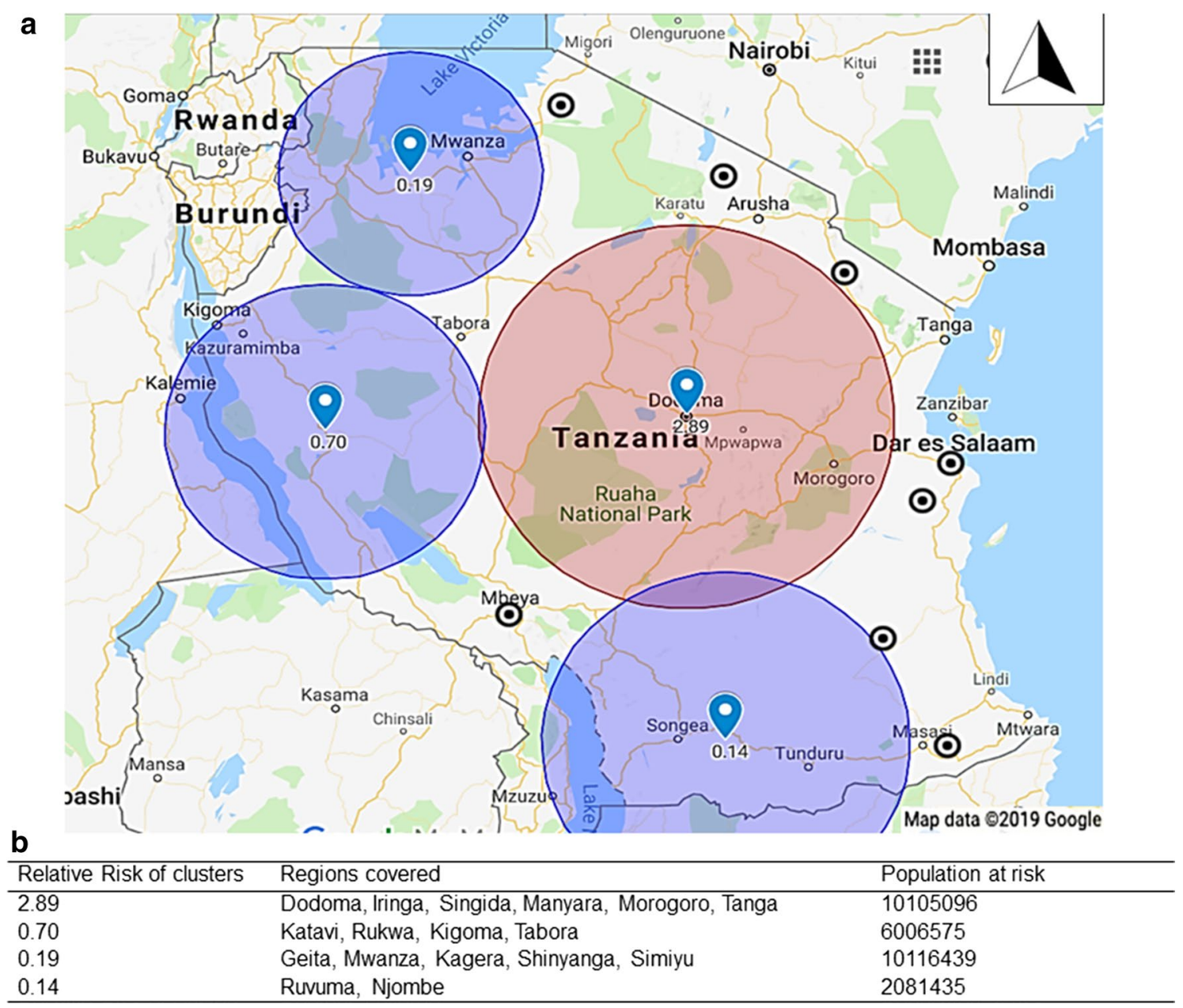

Fig. 2 Cholera hotspots in mainland Tanzanian and relative risks as identified by SatScan and displayed using Google map. a Mapping of the relative risks of cholera within the identified hotspots. $\mathbf{b}$ Regions at risk and population size in the identified cholera hotspots

data are not available from the smallest geographical structures in affected countries [6,8]. Reliability of data also includes consistency in case definitions because only a small proportion of suspected cases are laboratory confirmed and may bias identification of priority areas where interventions are needed [5].

Compared to previous studies in the DRC, Uganda, India and Zanzibar [6-9] which had cholera data and exposure variables from districts, the available regional data in Tanzania were not able to detect many risk factors investigated against the incidence of cholera. The rainfall pattern, both before and during the year of epidemics did not significantly affect the cholera incidence in mainland Tanzania based on currently available data $(\mathrm{p}=0.07 ; 0.14$, respectively, Additional file 1$)$. This could mean that in reality there is no positive correlation between rainfall and risk for cholera in mainland
Tanzania. Nevertheless, cholera is normally expected to have a seasonal pattern as is the case in Zanzibar and elsewhere $[7,20,21]$. Only water perimeter in a region was significantly associated with incidence of cholera with a $1.5 \%$ increase in incidence for $100 \mathrm{~km}$ increase in water perimeter (IRR 1.015; 95\% CI 1.001 to 1.030 ; $p=0.042$, Fig. 3). This correlates findings of the hotspots analyses where three significant clusters covered regions around the Great Lakes. Living near water bodies mainly great Lakes seems therefore a significant risk factor for cholera which has also been documented globally [22]. Recent findings in Tanzania where $V$. cholerae $\mathrm{O} 1$ isolated from Lake Victoria were phylogenetically identical to those causing cholera outbreaks in the African Great Lakes region further illustrates the association between Lakes and cholera [23]. 


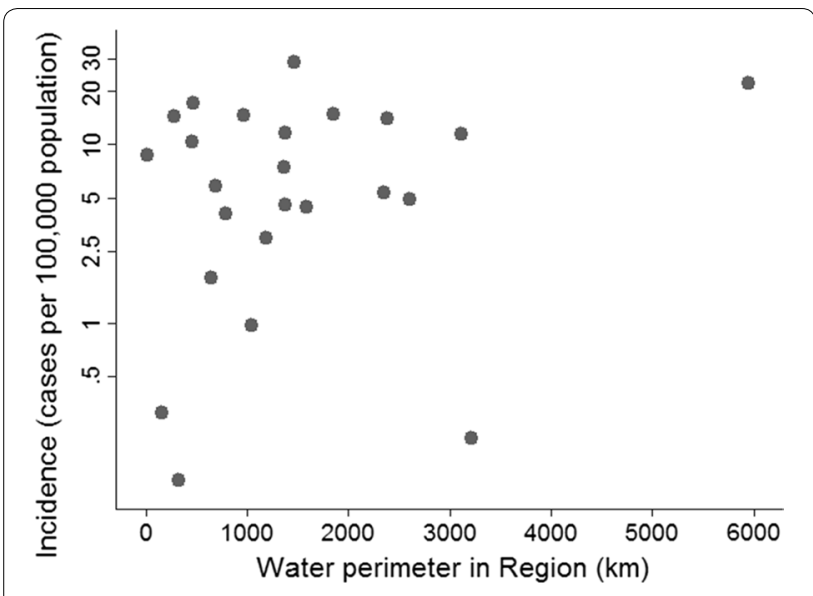

Fig. 3 Relationship between cholera incidence (log incidence per 100,000 population) and total water perimeter (in kilometer) in a region. One region has been omitted, i.e. Kagera because of zero reporting

\section{Limitations}

The principal limitation of this study is the weakness of the cholera surveillance system in Tanzania to provide disaggregated data available weekly and at district levels in order to serve as data for action to support the roadmap for cholera control. Moreover, there is a low incidence of cholera in Tanzania based on reported data and this could be attributed to the fact that reporting cholera has negative impacts on tourism and exports of affected countries, leading to underreporting. Furthermore, Dar es Salaam is one on of the main cities experiencing recurrent cholera outbreaks in Tanzania but was not identified as part of the hotspot areas because data were aggregated at regional level and could bias the spatial analysis. Data aggregated at regional levels were not able to detect rainfall as a significant risk factor on cholera incidence. During data curation we observed that only a small proportion of suspected cases are laboratory confirmed and this may affect the consistency in case definitions and identification of priority areas where interventions are needed.

\section{Supplementary information}

Supplementary information accompanies this paper at https://doi. org/10.1186/s13104-019-4731-0.

Additional file 1. Number of cholera reported cases and deaths by region and cholera risk factors.

\section{Abbreviation}

DRC: Democratic Republic of Congo.

\section{Acknowledgements}

We are grateful to Dr. George C.Kauki and Janneth Mghamba from the Epidemiology and Disease Control Section of the Ministry of Health Community Development, Gender Elderly and Children of Tanzania for providing the data.

\section{Authors' contributions}

YH collected the data, carried out initial descriptive statistics and GIS data analyses, constructed graphs, made data interpretation and drafted the original Manuscript. KM carried out the regression analyses, result interpretation, and revised the final manuscript. JK provided guidance in GIS data analysis and revised the final manuscript. RM, JO and AD provided guidance in data interpretation and critical revision of the final manuscript. KM and $A D$ supervised this study and all authors have approved the final version of the manuscript for submission.

\section{Funding}

Authors received funding from the Danish International Development Assistance (Danida) through the project "Innovations and Markets for Lake Victoria Fisheries" (IMLAF); Grant Number: DFC File No. 14-P01-TAN and the International Foundation for Sciences; Grant Number: 1-2-A-6100-1.

The funding bodies had no roles in the design of the study and collection, analysis, and interpretation of data and in writing the manuscript.

\section{Availability of data and materials}

The dataset supporting this study has been submitted in Additional file 1.

\section{Ethics approval and consent to participate}

Not applicable. The study involved retrospective surveillance data.

\section{Consent for publication}

Not applicable.

\section{Competing interests}

The authors declare that they have no competing interests.

\section{Author details}

${ }_{1}^{1}$ Department of Veterinary and Animal Sciences, Faculty of Health and Medical Sciences, University of Copenhagen, 1870 Frederiksberg C, Copenhagen, Denmark. ${ }^{2}$ Division of Infectious Disease Preparedness, Statens Serum Institut, Artillerivej 5, 2300 Copenhagen, Denmark. ${ }^{3}$ Department of Veterinary Medicine and Public Health, College of Veterinary and Biomedical Sciences, Sokoine University of Agriculture, PO Box: 3021, Morogoro, Tanzania. ${ }^{4}$ School of Chemical and Biomedical Engineering, Nanyang Technological University, Singapore, Singapore.

Received: 3 September 2019 Accepted: 14 October 2019

Published online: 21 October 2019

\section{References}

1. Lessler J, Moore SM, Luquero FJ, McKay HS, Grais R, Henkens M, et al. Mapping the burden of cholera in sub-Saharan Africa and implications for control: an analysis of data across geographical scales. Lancet. 2018;391:1908-15. https://doi.org/10.1016/S0140-6736(17)33050-7.

2. Mengel MA, Delrieu I, Heyerdahl L, Gessner BD. Cholera outbreaks in Africa. In: Nair GB, Takeda Y, editors. Cholera outbreaks. Berlin: Springer; 2014. p. 117-44. https://doi.org/10.1007/82_2014_369.

3. WHO. Cholera-United Republic of Tanzania. WHO. 2018. http://www. who.int/csr/don/12-january-2018-cholera-tanzania/en/. Accessed 15 Oct 2018.

4. WHO. Ending cholera. A global roadmap to 2030. 2017. http://www.who. int/cholera/publications/global-roadmap/en/. Accessed 15 Oct 2018.

5. Azman AS, Moore SM, Lessler J. Surveillance and the global fight against cholera: setting priorities and tracking progress. Vaccine. 2019. https:// doi.org/10.1016/j.vaccine.2019.06.037.

6. Ali M, Sen Gupta S, Arora N, Khasnobis P, Venkatesh S, Sur D, et al. Identification of burden hotspots and risk factors for cholera in India: an observational study. PLoS ONE. 2017;12:e0183100. https://doi.org/10.1371/ journal.pone.0183100. 
7. Bi Q, Abdalla FM, Masauni S, Reyburn R, Msambazi M, Deglise C, et al. The epidemiology of cholera in Zanzibar: implications for the zanzibar comprehensive cholera elimination plan. J Infect Dis. 2018. https://doi. org/10.1093/infdis/jiy500.

8. Bwire G, Ali M, Sack DA, Nakinsige A, Naigaga M, Debes AK, et al. Identifying cholera "hotspots" in Uganda: an analysis of cholera surveillance data from 2011 to 2016. PLOS Negl Trop Dis. 2017;11:e0006118. https://doi. org/10.1371/journal.pntd.0006118.

9. Ingelbeen B, Hendrickx D, Miwanda B, van der Sande MAB, Mossoko M, Vochten $\mathrm{H}$, et al. Recurrent cholera outbreaks, Democratic Republic of the Congo, 2008-2017. Emerg Infect Dis. 2019;25:856-64. https://doi. org/10.3201/eid2505.181141.

10. Bwire G, Mwesawina M, Baluku Y, Kanyanda SSE, Orach CG. Cross-border cholera outbreaks in sub-Saharan Africa, the mystery behind the silent illness: what needs to be done? PLoS ONE. 2016;11:e0156674. https://doi. org/10.1371/journal.pone.0156674.

11. NBS. Tanzania Census 2012-National Bureau of Statistics. 2012. http:// dataforall.org/dashboard/tanzania/. Accessed 29 Oct 2018.

12. DIVA-GIS. Download data by country|DIVA-GIS. 2018. http://www.divagis.org/gdata. Accessed 23 Sept 2018.

13. Phelps M, Perner ML, Pitzer VE, Andreasen V, Jensen PKM, Simonsen L. Cholera epidemics of the past offer new insights into an old enemy. J Infect Dis. 2018;217:641-9. https://doi.org/10.1093/infdis/jix602.

14. Phelps MD, Azman AS, Lewnard JA, Antillón M, Simonsen L, Andreasen $V$, et al. The importance of thinking beyond the water-supply in cholera epidemics: a historical urban case-study. PLOS Negl Trop Dis. 2017;11:e0006103. https://doi.org/10.1371/journal.pntd.0006103.

15. Sasaki S, Suzuki H, Igarashi K, Tambatamba B, Mulenga P. Spatial analysis of risk factor of cholera outbreak for 2003-2004 in a peri-urban area of Lusaka. Zambia. Am J Trop Med Hyg. 2008;79:414-21.

16. Lugongo B. Tanzania: Government Move to Dodoma Now At 86 Per Cent. Tanzania Daily News (Dar es Salaam). 2019. https://allafrica.com/stori es/201902060401.html. Accessed 8 Jul 2019.
17. Bompangue D, Giraudoux P, Handschumacher P, Piarroux M, Sudre B, Ekwanzala M, et al. Lakes as source of cholera outbreaks, Democratic Republic of Congo. Emerg Infect Dis. 2008;14:798-800. https://doi. org/10.3201/eid1405.071260.

18. Nkoko D, Giraudoux P, Plisnier P-D, Tinda A, Piarroux M, Sudre B, et al. Dynamics of cholera outbreaks in Great Lakes Region of Africa, 19782008. Emerg Infect Dis. 2011. https://doi.org/10.3201/eid1711.110170.

19. Rajasingham A, Hardy C, Kamwaga S, Sebunya K, Massa K, Mulungu J, et al. Evaluation of an emergency bulk chlorination project targeting drinking water vendors in cholera-affected wards of Dar es Salaam and Morogoro, Tanzania. Am J Trop Med Hyg. 2019. https://doi.org/10.4269/ ajtmh.18-0734.

20. Emch M, Feldacker C, Islam MS, Ali M. Seasonality of cholera from 1974 to 2005: a review of global patterns. Int J Health Geogr. 2008;7:31. https:// doi.org/10.1186/1476-072X-7-31.

21. Lemaitre J, Pasetto D, Perez-Saez J, Sciarra C, Wamala JF, Rinaldo A. Rainfall as a driver of epidemic cholera: comparative model assessments of the effect of intra-seasonal precipitation events. Acta Trop. 2019;190:235-43. https://doi.org/10.1016/j.actatropica.2018.11.013.

22. Islam MS, Zaman MH, Islam MS, Ahmed N, Clemens JD. Environmental reservoirs of Vibrio cholerae. Vaccine. 2019. https://doi.org/10.1016/j.vacci ne.2019.06.033.

23. Hounmanou YMG, Leekitcharoenphon P, Hendriksen RS, Dougnon TV, Mdegela RH, Olsen JE, et al. Surveillance and genomics of toxigenic Vibrio cholerae $\mathrm{O} 1$ from fish, phytoplankton and water in Lake Victoria, Tanzania. Front Microbiol. 2019. https://doi.org/10.3389/fmicb.2019.00901.

\section{Publisher's Note}

Springer Nature remains neutral with regard to jurisdictional claims in published maps and institutional affiliations.
Ready to submit your research? Choose BMC and benefit from:

- fast, convenient online submission

- thorough peer review by experienced researchers in your field

- rapid publication on acceptance

- support for research data, including large and complex data types

- gold Open Access which fosters wider collaboration and increased citations

- maximum visibility for your research: over 100M website views per year

At BMC, research is always in progress.

Learn more biomedcentral.com/submissions 